$\xi=-1$

\title{
Prediction of by-Products from Wet Air Oxidation Module for Sludge Treatment of Produced Water
}

\author{
Eun-bi Cho*, Choon-hyung Kang** and In-ju Hwang* \\ *Department of Future Technology and Convergence Research, Korea Institute of Civil Engineering and Building Technology, \\ Goyang 10223, Korea \\ **Department of Chemical Engineering, Chonnam National University, 61186, Gwangju, Korea \\ *Corresponding author E-mail: ijhwang@kict.re.kr
}

\begin{abstract}
This study presents and verifies the deep-well wet air oxidation (WAO) reaction model for treating organic sludge (among the various by-products discharged from produced water treatment facilities) for recycling, and predicts the reaction characteristics. The deep-well WAO reaction model is established theoretically and a simulation model is developed. The validity of the simulation model is examined by comparing the modeled pressure change inside the reactor with that given by a model developed in a previous study. In terms of the pressure profile inside the reactor, the developed simulation model shows a $2.3 \%$ difference from the previously proposed model. It is confirmed that the increase in reaction pressure and residence time inside the deep-well WAO reactor improves organic decomposition by increasing the oxygen mass transfer rate in water containing such organics.
\end{abstract}

Keywords: Wet air oxidation, Deep well reactor, Producer water, Sludge treatment, by-product

\section{Introduction}

The treatment of oil, gas, and environmental waste generates produced water, which contains a complex mixture of organic and inorganic compounds. The criteria for the use and treatment of such produced water are being reinforced to reduce its environmental impact, and various types of treatment technology are under development. In particular, for the treatment of organic waste with significant environmental impact, physical, chemical, and biological treatment methods such as filters, membrane separation, dissolved air precipitation, chemical oxidation, and aerobic treatment have been developed.

Previously, Rajab et al. [1] examined the performance of the forward osmosis process for treating produced water, and demonstrated the possibility of dissolved organics removal. Shokrollahzadeh et al. [2] oxidized produced water separated from the gas flow in an Iranian gas refinery using hydrogen peroxide, ozone, and calcium hypochlorite, for reuse as fire-fighting water. Further, Dwyer and Mcdonald [3] demonstrated that the oxidation method using ozone removes more organics than the membrane separation method when treating water produced by an oil and gas extraction process in the Four Corners area of New Mexico. However, Ahmadun et al. [4] reported difficulty in removing dissolved elements such as acetic acid from produced water using current technology, and stated that these types of technology incur high initial and operation costs for produced water treatment while also producing hazardous sludge.

The wet air oxidation (WAO) reaction has been investigated for treatment of organic waste occurring in the produced water treatment process. In experiments on the tubular-flow-type WAO reaction for the treatment of wastewater containing phenol, a nonbiodegradable substance. However, the ground installation condi- tions for the existing WAO reactor are limited, because pressurization power is required to maintain a high pressure; thus, the life cycle operation cost is high.

To address such problems, the deep-well WAO reactor, which can dramatically reduce the power cost, has been attracting growing research attention. Gran-Heedfeld et al. [5] have reported that the COD can be reduced by $65 \square 90 \%$ when the temperature of the lower part of the reactor is $280 \square \mathrm{C}$, based on numerical calculations concerning a deep-well WAO reactor for wastewater.

Kodra and Balakotaiah [6] have examined the effects of the organic waste concentration, the amount of oxygen injected into the reactor, the inlet pressure, and the reactor length on the organic waste decomposition rate in a steady-state deep-well reactor, through numerical calculation of the WAO wastewater reaction.

The aim of this study is to develop reaction characteristic prediction software that can be utilized for the design and operation optimization of a deep-well WAO reaction plant for treating the organics of produced water. A method to treat these organics using the deep-well tubular-flow-type WAO reactor is proposed, and a simulation model is developed based on related theories to predict the reaction characteristics. The simulation model feasibility is then examined through comparison with a previously developed model. The design and operation variables that significantly affect the conversion rate of the reaction in the deep-well WAO reactor are assessed

\section{Analysis Model}

\subsection{WAO Reaction in Deep-Well Reactor}

Various methods are available to treat the dispersed oil, grease, soluble organics, suspended particles and sand, dissolved gas, and salt contained in produced water. In this study, the WAO method 


$$
\begin{aligned}
& \mathrm{C}_{5} \mathrm{H}_{7} \mathrm{O}_{2} \mathrm{~N}+7 \mathrm{O}_{2} \stackrel{k_{1}}{\rightarrow} 5 \mathrm{CO}_{2}+3 \mathrm{H}_{2} \mathrm{O}+\mathrm{HNO}_{3}, \\
& \mathrm{C}_{5} \mathrm{H}_{7} \mathrm{O}_{2} \mathrm{~N}+5 \mathrm{O}_{2} \stackrel{k_{2}}{\rightarrow} \mathrm{C}_{2} \mathrm{H}_{4} \mathrm{O}_{2}+3 \mathrm{CO}_{2}+\mathrm{H}_{2} \mathrm{O}+\mathrm{HNO}_{3}, \\
& \mathrm{C}_{2} \mathrm{H}_{4} \mathrm{O}_{2}+2 \mathrm{O}_{2} \stackrel{k_{3}}{\rightarrow} 2 \mathrm{CO}_{2}+2 \mathrm{H}_{2} \mathrm{O} .
\end{aligned}
$$

In the case of a continuous parallel reaction, the compositions of the intermediate and final substances vary depending on the reaction conditions such as $T$ and the residence time. The reaction rate equations can be defined from the reaction mechanism, as follows. (Here, the oxidation reaction is regarded as a first-order reaction with a reaction degree $(n)$ of 1 .)

$$
\begin{aligned}
& r_{C_{5} H_{7} O_{2} N}=\left(k_{1}+k_{2}\right) C_{C_{5} H_{7} O_{2} N}^{n}=\left(k_{0_{1}} e^{-\frac{E_{1}}{R T}}+\right. \\
& \left.k_{0_{2}} e^{-\frac{E_{2}}{R T}}\right) C_{C_{5} H_{7} O_{2} N}^{n} \\
& r_{C_{2} H_{4} O_{2} N}=k_{3} C_{C_{2} H_{4} O_{2} N}^{n}-k_{2} C_{C_{5} H_{7} O_{2} N}^{n}= \\
& k_{0_{3}} e^{-\frac{E_{3}}{R T}} C_{C_{2} H_{4} O_{2} N}^{n}-k_{0_{2}} e^{-\frac{E_{2}}{R T} C_{C_{5} H_{7} O_{2} N}^{n}}
\end{aligned}
$$

The value of $k$ was calculated through equation (2.4) using the $k_{0}$ and $E$ data derived by Ahn [9] under the WAO conditions $\left(180-240^{\circ} \mathrm{C}\right.$ and $\left.3.04 \mathrm{MPa}\right)$ of the perfectly stirred reaction system.

In general, the non-random two-liquid (NRTL) model is used to design a wastewater treatment process. Previously, Olsson and Zacchi used the NRTL equation for gas-liquid and liquid-liquid equilibrium calculations to treat seven hazardous organic compound condensates from Kraft mill wastes [10]. Further, Randa $e$ al. used the NRTL equation to calculate the mass balance and mixture properties in a process simulation for carboxylic acid recovery from wastewater [11]. Therefore, the NRTL model was used in this study to simulate decomposition of the organic substance $\left(\mathrm{C}_{5} \mathrm{H}_{7} \mathrm{O}_{2} \mathrm{~N}\right)$ by the deep-well WAO reactor

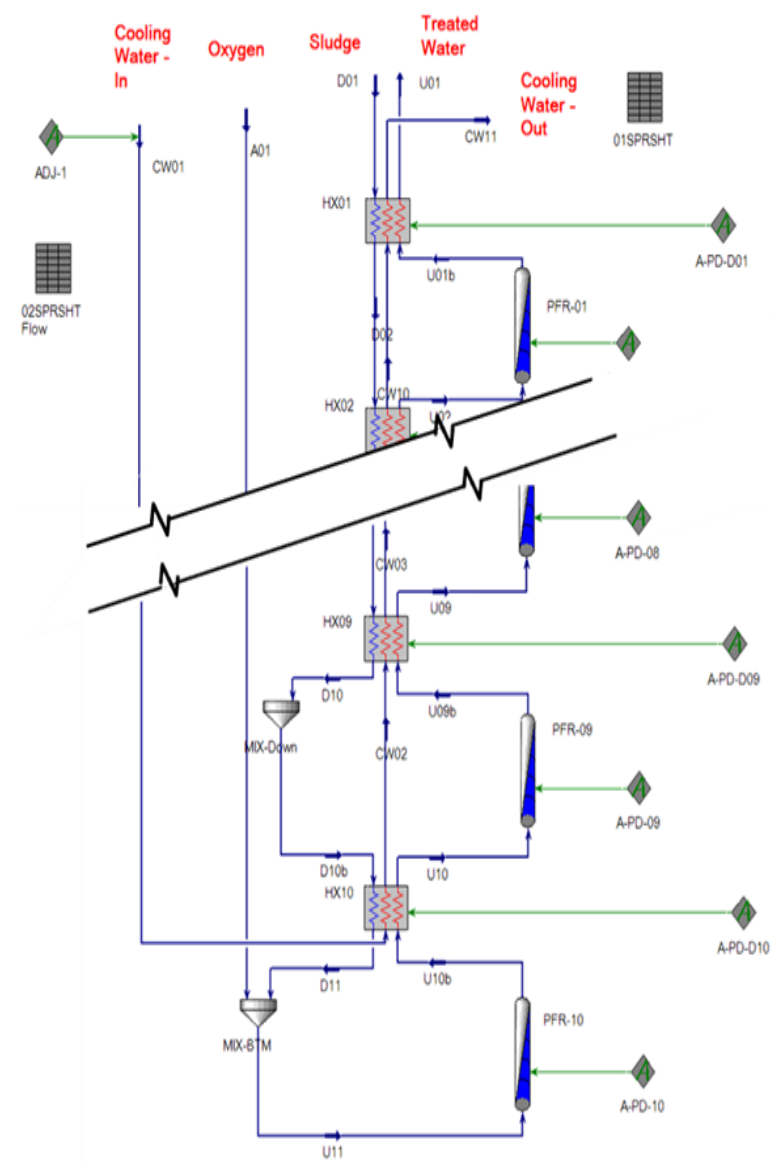

Fig.3. Simulation model of simplified deep-well wet oxidation reactor with HYSYS blocks.
The library of HYSYS V10, the process simulation software program used in this study, does not include the deep-well WAO reactor. Therefore, a model similar to the deep-well WAO reactor was simulated using two units, as shown in Fig. 3. The HYSYS blocks and streams used here are summarized in Table 1.

The system in which the up flow, down flow, and heat exchange of the cooling medium occur was expressed as a multi-stream heat exchanger, whereas the system in which the oxidation reaction occurs in the middle tube was expressed as a PFR. As the heat transfer between the oxidizing agent that flows down from the top of the reactor and the down flow is negligible, a mixer was used to mix the oxidizing agent with organic wastewater and to inject the mixed flow into the reactor.

In the reactor model, the $p$ at each location must be derived by calculating the total pressure drop using the flow velocity and density values obtained from the simulation. The total pressure drop $\Delta p_{\text {total }}$ is the sum of the static, momentum, and frictional pressure drops ( $\Delta p_{\text {static }}, \Delta p_{\text {mom }}$, and $\Delta p_{\text {frict }}$, respectively), as follows:

$p_{\text {total }}=\Delta p_{\text {static }}+\Delta p_{\text {mom }}+\Delta p_{\text {frict }}$

As $p$ varies with the elevation head in the deep-well reactor, the reactor was divided into ten units of $150 \mathrm{~m}$. Then, $\Delta p_{\text {total }}$ was calculated by inputting equation (2.7) into a spreadsheet so that the calculated $\Delta p_{\text {total }}$ values were then set for entry into each reactor model.

Table 1: Blocks used in Aspen HYSYS

\begin{tabular}{|l|l|c|c|}
\hline \multicolumn{2}{|c|}{ Category } & \multicolumn{2}{|c|}{ HYSYS Model } \\
\cline { 3 - 4 } \multicolumn{2}{|l|}{ Btream } & Name \\
\hline $\begin{array}{l}\text { - Oxidizing } \\
\text { agent flow }\end{array}$ & Oxidizing agent & Stream & A01 \\
\hline - Down flow & Organic wastewater & Stream & D01-D11 \\
\hline - Up flow & Treated wastewater & Stream & U01-U11 \\
\hline $\begin{array}{l}\text { - Cooling } \\
\text { medium flow }\end{array}$ & Cooling water & Stream & CW01-CW11 \\
\hline Model & \multicolumn{3}{|l}{} \\
\hline $\begin{array}{l}\text { - Deep-well } \\
\text { reactor }\end{array}$ & Reactor & PFR & PFR01-PFR10 \\
\cline { 2 - 4 } & $\begin{array}{l}\text { Multi-stream heat } \\
\text { exchanger }\end{array}$ & $\begin{array}{l}\text { LNG Ex- } \\
\text { changer }\end{array}$ & HX01-HX10 \\
\cline { 2 - 4 } & Mixer & Mixer & MIX-BTM \\
\hline
\end{tabular}

To verify the deep-well WAO reactor simulation model, the mathematical model developed by Kodra and Balakotaiah [6] was compared with the simulation model developed using HYSYS in this study, using the calculated $p$, density, and organic waste conversion. Note that the flow rate at each location in the reactor is affected by $T$. In other words, after $T$ is determined, changes in the flow rate, density, and $p$ can be calculated according to the volume velocity for the reference $T$. Therefore, the $T$ values in the literature [6] were taken as the initial values for comparing the calculated density and $p$ values.

In this study, the input conditions of the deep-well WAO rector model were set to be identical to those of Ref. [6], as detailed in Table 2. The $p$ and conversion rate calculated from the reactor model were compared with the calculation results of Kodra and Balakotaiah [6] for verification. Then, the factors affecting organic waste decomposition were analyzed using the verified model.

Table 2: Input values used in simulation model

\begin{tabular}{|l|c|c|}
\hline \multicolumn{2}{|c|}{ Items } & Value \\
\hline Reaction-stream inlet velocity & $\mathrm{m} / \mathrm{s}$ & 0.5 \\
\hline Inlet temperature & ${ }^{\circ} \mathrm{C}$ & 20.0 \\
\hline Inlet pressure & $\mathrm{MPa}$ & 2 \\
\hline Weight fraction of organics in feed & wt. $\%$ & 1.0 \\
\hline
\end{tabular}




\begin{tabular}{|l|c|c|}
\hline Reactor length & $\mathrm{m}$ & 1,500 \\
\hline Reaction zone (oxygen injection) & $\mathrm{m}$ & 1,500 \\
\hline $\begin{array}{l}\text { Excess of oxygen injected in reaction } \\
\text { mixture }\end{array}$ & $\mathrm{mol} \%$ & 10.0 \\
\hline Heat transfer coefficient & $\mathrm{W} \cdot \mathrm{m}^{2} / \mathrm{K}$ & 2.0 \\
\hline
\end{tabular}

\subsection{Influence Factor Analysis}

Fig. 6(a) shows the $\mathrm{C}_{5} \mathrm{H}_{7} \mathrm{O}_{2} \mathrm{~N}$ and $\mathrm{C}_{2} \mathrm{H}_{4} \mathrm{O}_{2}$ up-flow flow rates according to the inlet $p$. When the inlet $p$ was set to 1,2 , and $3 \mathrm{MPa}$, the $p$ values at the reactor bottom were $13.3,14.3$, and 16.3 MPa, respectively, and most organics were decomposed at locations $1,380 \mathrm{~m}$ from the inlet. Changes in the inlet $p$ do not appear to affect the reaction significantly, because the reaction $p$ is sufficiently high. Fig. 6(b) shows the $\mathrm{C}_{5} \mathrm{H}_{7} \mathrm{O}_{2} \mathrm{~N}$ and $\mathrm{C}_{2} \mathrm{H}_{4} \mathrm{O}_{2}$ up-flow flow rates when the oxygen injection rate was $50 \%, 75 \%$, and $110 \%$. When the oxygen injection rates were $50 \%$ and $75 \%, 69 \%$ and $99 \%$ of the $\mathrm{C}_{5} \mathrm{H}_{7} \mathrm{O}_{2} \mathrm{~N}$ was decomposed, while $0 \%$ and $3 \%$ of $\mathrm{C}_{2} \mathrm{H}_{4} \mathrm{O}_{2}$ (created via $\mathrm{C}_{5} \mathrm{H}_{7} \mathrm{O}_{2} \mathrm{~N}$ decomposition) was decomposed. This is because the conditions for $\mathrm{C}_{5} \mathrm{H}_{7} \mathrm{O}_{2} \mathrm{~N}$ and $\mathrm{C}_{2} \mathrm{H}_{4} \mathrm{O}_{2}$ decomposition could not be met, when the injected oxygen requirement was not met. When the oxygen injection rate was $110 \%, 100 \%$ of the $\mathrm{C}_{5} \mathrm{H}_{7} \mathrm{O}_{2} \mathrm{~N}$ and $66 \%$ of the $\mathrm{C}_{2} \mathrm{H}_{4} \mathrm{O}_{2}$ was decomposed. Thus, even when the oxygen requirement for complete decomposition was surpassed, there were cases for which the conversion rate is low. This appears to be because the efficiency of mass transfer through the gas-liquid contact is low. Therefore, it is necessary to optimize the operation conditions by simultaneously changing the $p$, and oxygen amount to improve the gas-liquid contact efficiency.

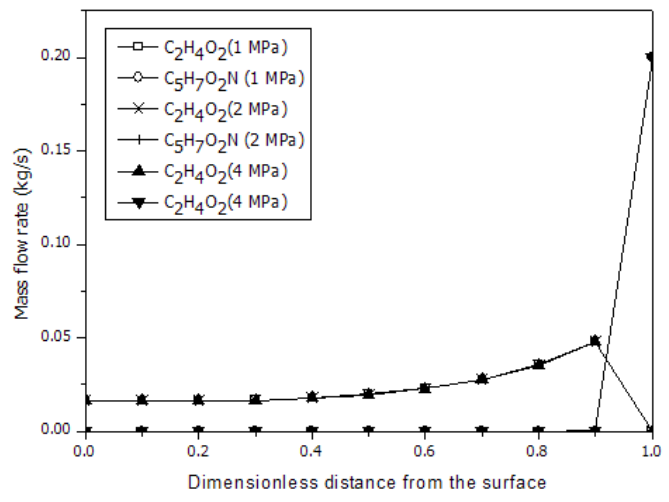

(a) approached the crit ened hydrogen bond increases the solubility of the polar organic substance and the maintained liquid state increases the oxygen solubility, making it possible to meet the minimum oxygen requirement. Furthermore, the high- $T$ condition increases the diffusion coefficient of oxygen and the $k$ of the oxidation reaction. In other words, the high-T, high- $p$ critical condition at the reactor bottom increases the oxygen mass transfer rate in the pollutantcontaining water, thereby decomposing most organics into $\mathrm{CO}_{2}$ and low-molecular-weight organic acids during oxidation. The conversion rate difference at the reactor bottom for the ref. and simul. model was $1.6 \%$, a low error.

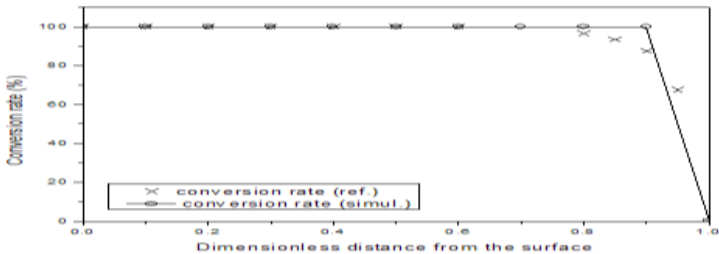

(a) Pressure

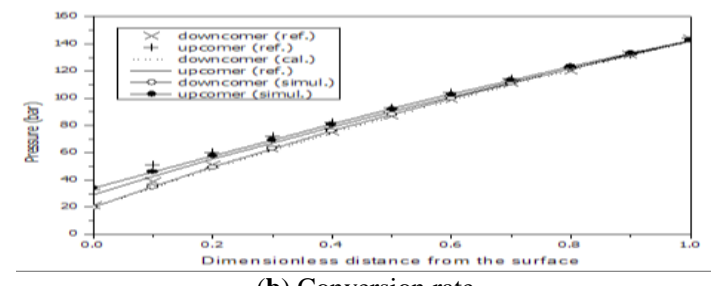

(b) Conversion rate

Fig. 5: Characteristics profiles of deep-well WAO reactor.

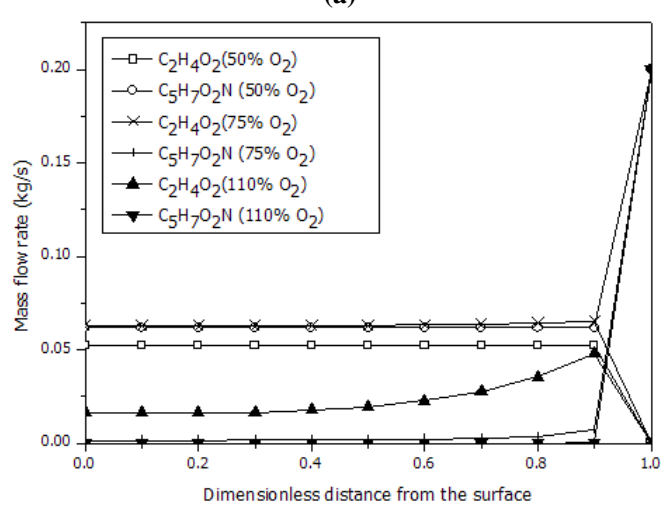

(b)

Fig. 6: Influence of (a) feed p, and (b) oxygen content on $\mathrm{C} 2 \mathrm{H} 4 \mathrm{O} 2$, $\mathrm{C} 5 \mathrm{H} 7 \mathrm{O} 2 \mathrm{~N}$ decomposition.

\section{Conclusion}

In this study, the deep-well wet air oxidation (WAO) reaction model for treating the organic sludge discharged from produced water treatment facilities for recycling was proposed and verified, and its characteristics were analyzed.

For the pressure and conversion rate profiles in the reactor, the simulation model developed of this study exhibited $2.3 \%$, and $1.6 \%$ differences compared to the results given by a model developed in a previous study, indicating that the accuracy can be improved by modifying the density and pressure models according to the multiphase flow. In addition, it was confirmed that the decomposition 
of organics and organic acids in the deep-well WAO reaction is proportional to the inlet pressure.

It is expected that the proposed reaction model can be effectively applied to the treatment of organic sludge contained in produced water.

\section{Acknowledgement}

This research was supported by a grant(18IFIP-B089072-05\#) from Plant Research Program funded by Ministry of Land, Infrastructure and Transport of Korean government.

\section{References}

[1] Abousnina, R. M. and Nghiem, L. D., Removal of dissolved organic from produced water by forward osmosis. Desalinationa and Water Treatment, 52(2014), 570-579.

[2] Shokrollahzadeh, S., Golmohammad, F., Naseri, N., Shokouhi, H and Arman-mehr, M., Chemical oxidation for removal of hydrocarbons from gas-field produced water. Procedia Engineering, 42(2012), 942-947.

[3] Dwyer, B. P. and McDonald, F., Treatment of Oil \& Gas Produced Water. Sandia National Laboratories, (2016), 3-30.

[4] Ahmadun, F. R., Pendashtech, A., Abdullah, L. C., Biak, D. R. A. Madaeni, S. S. and Abidin, Z. Z., Review of technologies for oil and gas produced water treatment. Journal of Hazardous Materials, 170(2009), 530-551.

[5] Gran-Heedfeld, J., Schluter, S. and Daun, M., Modelling and simulation of a deep well reactor for the wet air oxidation of sewage sludge. Chemical Engineering and Processing, 34(1995), 121-126.

[6] Kodra, D. and Balakotaiah, V., Two-phase model for subcritical oxidation of aqueous wastes in a deep-well reactor. Hazardous Waste \& Hazardous Materials, 10(1993), 247-271.

[7] Lixiong, L., Peishi, C. and Earnest, F. G., Generalized kinetic model for wet oxidation organic compounds. American Institute of Chemical Engineers, 37(1991), 1687-1697.

[8] Bernal, J. 1., Miguelez, J. R. P., Sanz, E. N., Ossa, E. M., Wet air oxidation of oily wastes generated aboard ships: kinetic modeling. Journal of Hazardous Materials, 67(1999), 61-73.

[9] Ahn, J., Kinetics Study for Wet Air Oxidation of Sewage Sludge. Korean Society of Environmental Engineers, 27(2005), 746-752.

[10] Olsson, J. and Zacchi, G., Simulation of the condensate treatment process in a Kraft pulp mill. Chemical Engineering and Technology, 24(2001), 195-203

[11] Wytcherley, R. W., Gentry, J. C. and Gualy, R. G., Method of recovering carboxylic acids from dilute aqueous streams. US Patent, (1996), 5,492,625. 